\title{
Prevalence of airway symptoms among hairdressers in Bergen, Norway
}

\author{
B E Hollund, B E Moen, S H Lygre, E Florvaag, E Omenaas
}

\begin{abstract}
Objective-To assess respiratory symptoms among hairdressers in Norway.

Methods-The study was based on a questionnaire sent to 100 hairdressers $(91 \%$ responding) and 95 office workers (84\% responding). The questionnaire sought information about allergy, respiratory symptoms in the past year, and symptoms after exposures to different types of pollutants, working conditions, and smoking habits. A population based control group was established because the hairdressers and office workers differed in age and smoking habits.
\end{abstract}

Results-The prevalence of respiratory symptoms in the past year did not differ significantly between hairdressers and office workers after adjusting for age, atopy, and smoking. The hairdressers over 40 years of age reported significantly more symptoms-such as wheezing and breathlessness-in the past year than the office workers of the same age. Compared with the population based control group, both hairdressers younger than 30 and those over 40 reported more symptomssuch as breathlessness in the past year. The oldest hairdressers reported such symptoms as wheezing and breathlessness more often than did the younger hairdressers. These differences in breathlessness were significant after adjusting for smoking and wheezing. The same trend was not found among the office workers. The hairdressers reported significantly more wheezing, breathlessness, runny eyes, and blocked or runny nose from exposure to hair dyes, permanent oils, bleaching powder, and other chemicals used in a hairdressing salon, compared with the office workers. Prevalence of symptoms during exposure to other types of generel pollutants was similar in the two groups.

Conclusions-Hairdressers are exposed to low levels of various irritating chemicals every day. The prevalences of acute symptoms related to the exposure of hairdressers to hairdressing chemicals are very high. Hairdressers, especially the oldest hairdressers, have more asthma-like symptoms than the control groups. (Occup Environ Med 2001;58:780-785)

Keywords: hairdresser; allergy; asthma

Exposure to high concentrations of gases, vapours, and fumes in a workplace may cause respiratory symptoms and bronchoconstriction by various pathophysiological mechanisms. This has been found in workers with high exposure to organic dust and paint, including welding, ${ }^{1}$ and may be caused by the direct effect on irritant receptors or mucosal inflammation of the bronchus. Of current interest is whether workplace exposure to low concentrations of gases, vapours, and fumes may cause respiratory symptoms and airway obstruction.

Employees in a hairdressing salon are periodically exposed to various chemicals in permanent oils, hair dyes, and hair lacquers capable of producing respiratory symptoms. ${ }^{2-4}$ Some of these chemicals are considered to be allergens; other chemicals are irritants, and both may cause acute, non-specific respiratory tract reactions shortly after exposure. Persulfate salts and hair dyes have, for example, been associated with chronic and recurring asthma in hairdressers and chemical workers. ${ }^{5-9}$

Little is known about the prevalence of different types of airway symptom caused by these highly reactive, low molecular weight chemicals present in hairdressing salons. Such knowledge would be important in preventing chemical hazards in these workplaces. ${ }^{10}$

The aims of this study were to examine the self reported prevalence of respiratory symptoms among hairdressers and to estimate the risk of such symptoms among hairdressers compared with two unexposed control groups.

\section{Material and methods}

POPULATION

The survey was a cross sectional study performed in the city of Bergen, on the southwestern coast of Norway. The study included hairdressers who were exposed to chemicals, and office staff served as unexposed controls. Both groups included women only.

To avoid a study dominated by hairdressers with a brief period of chemical exposure, the exposed group was restricted to 100 women who had worked as hairdressers for at least 2 years. The youngest hairdressers tend to do most of the hair washing and less of the work that may cause chemical exposure, and many of these young hairdressers change occupation often.

The hairdressers had worked in 35 different salons; $50 \%$ were members of the employers' federation and $50 \%$ were not. Both member salons and non-member salons were included, as they might differ in size and ventilation conditions.

Ninety five office workers from eight companies were invited to take part in the survey. The hairdressers and the office workers were 
selected from the same geographical area and were all city residents.

At this time indoor air and sick building syndrome were very common in Scandinavia. ${ }^{11}$ The women in our population knew that we were focusing on allergy and airway symptoms. During the study period we realised that the office workers were discussing indoor air problems more than hairdressers and we feared that office workers might not be a good control group. A population based control group was therefore obtained by including data from a population based cross sectional study in Bergen, performed in $1988 .{ }^{12}$ With an additional control group, it was possibile to compare the office workes with a population without the same focus on allergy and airway symptoms. The survey was a two phased cross sectional study performed in the city of Bergen and surrounding municipalities in the county of Hordaland on the south west coast of Norway. A random sample of 3740 people between 15 and 70 years old were sent a postal questionnaire and $90 \%$ responded. A new random sample of 1512 subjects were invited to a lung health examination and blood sampling, the response rate was $84 \%$. The purpose of this study was to estimate concentrations of $\operatorname{IgE}$ and prevalences of some specific IgE antibodies in a general population. Each hairdresser was age and sex matched to three controls drawn from this study.

QUESTIONNAIRE

The questionnaire was sent by post to the hairdressers and office staff in October 1995. It was accompanied by a letter outlining the aims of the study. The questionnaire sought information on atopy, respiratory symptoms, smoking habits, previous occupations, and working hours each week. The occurrence of symptoms in the past year was obtained as the main outcome. Questions concerning atopy, age, smoking habits, and previous occupations were included because these factors may influence the answers to questions on respiratory symptoms. The wording of the questions on respiratory symptoms were: (1) Do you ever have wheezing in your chest? (2) Are you breathless? (3) Do you have cough for 2 weeks or more? (4) Do you have runny eyes? (5) Do you have blocked or runny nose? (6) Do you have hoarseness? The preprinted answers were no, yes-daily, yes-weekly, yes-each month, or yesonce in a while. The questionnaire also contained two questions on previous allergic and atopic diseases: Have you ever had one of the diseases: eczema, urticaria, hay fever, or asthma? Have you ever been allergy tested by a practitioner or in hospital? The recipients were asked to pick one of the preprinted answers yes, no, or do not know. Furthermore we asked if anyone in their family (mother, father, sister, brother, own children) has ever had one of the diseases: eczema, urticaria, hay fever, or asthma? The recipients were asked to pick one of the pre-printed answers yes, no, or do not know. Previous surveys in Norway have validated the questions on respiratory symptoms ${ }^{13}$ and smoking habits. ${ }^{14}$
The questionnaire also contained questions about airway symptoms related to different types of pollutants: tobacco smoke, exhaust, perfume or spray, organic solvents or paint, pollen, animal hair, house dust mites, medicines, hair dyes, permanent oils, and bleaching powder. The preprinted answers were yes or no. Permanent oils, hair dyes, and hair bleach are capable of producing respiratory symptoms. The questionnaire also contained questions about how often they were dying or bleaching their hair and how often they were getting a permanent wave. The recipients were asked to select one of the preprinted answers: never; $1-5$ times in your life; $1-5$ times a year; and 1-5 times a month. The hairdresseres were asked how many hair treatment customers they had each week.

Atopy was considered to be present if the subject reported that she had had asthma, hay fever, urticaria, or atopic dermatitis at any time in her life. Asthmatic people were defined as those answering yes to the question: Have you ever been treated by a physician or hospital for asthma?

Subjects were classified as non-smokers if they had never smoked daily. Ex-smokers were those who had been smoking daily but stopped smoking before the study. Smokers were those who smoked daily at the time of the study. They were asked how many cigarettes they smoked daily.

The data from the population based control group were somewhat different from the data obtained from the hairdressers and the office workers. These data had been obtained from another self administered questionnaire. Questions comparable with those in our present questionnaire were used. The responses about wheezing and breathlessness in the past year in our questionnaire were compared with the responses from the population based control group about ever having experienced attacks of breathlessness and wheezing in their chest.

Also, data about smoking in the population based control group were used. They had been asked whether they were current smokers, ex-smokers, or had never smoked.

\section{STATISTICAL METHODS}

The differences between the groups in prevalences of dichotinous variables - such as atopy and smoking-were tested by $\chi^{2}$ test, and differences in continuous variables were tested by $t$ test.

Differences in self reported lifetime eczema, hay fever, and asthma symptom prevalences between hairdressers and office workers were examined in logistic regression analyses adjusting for age (years) and current smoking (yes or no).

We also ran analyses adjusting for smoking with the groups non-smoking, low smoking exposure ( $<10$ cigarettes/day) and high smoking exposure ( $>10$ cigarettes/day). However, as the results were unaltered we merely present the analyses based on adjustment for smoking as current versus non-smokers (yes $v$ no). 
Table 1 Age, occurrence of atopy, and smoking habits among hairdressers and a control group of office workers

\begin{tabular}{llll}
\hline & $\begin{array}{l}\text { Hairdresser } \\
(n=91)\end{array}$ & $\begin{array}{l}\text { Office worker } \\
(n=80)\end{array}$ & p Value \\
\hline Mean age (y) & 33 & 44 & $0.01 \dagger$ \\
$<30(\%)$ & 49 & 19 & \\
$31-40(\%)$ & 30 & 24 & \\
$>41(\%)$ & 21 & 57 & \\
Atopy: & & & \\
$\quad$ Yes (\%) & 65 & 60 & $0.05 \ddagger$ \\
Smoking & & & \\
Non-smoker (\%) & 25 & 46 & \\
$\quad$ Ex-smoker (\%) & 25 & 23 & \\
$\quad$ Current smoker(\%) & 50 & 32 & \\
Cigarettes/day (mean) & 12 & 9 & \\
Hair treatment customers/week (mean) & 13 & & \\
\end{tabular}

^Based on the question: "have you ever had: asthma, hay fever, or eczema?"

†Student's $t$ test.

$\ddagger \chi^{2}$ test.
We also examined differences in the prevalences of symptoms of wheezing, breathlessness, or runny nose after exposure to common irritants.

In similar analyses examining symptoms after exposures to hair treatment we included all hairdressers and only those office workers reporting any use of hair treatment products.

Each respiratory symptom was used as a dependent variable in a logistic regression analysis adjusting for age, atopy, and smoking habits.

Our power to detect small differences in symptom reporting between the hairdressers and office workers was low. For example, our power was $<20 \%$ for detecting a significant difference in the prevalence of wheezing (35\% $v 29 \%$ ) between the two groups (with a type I error of 0.10).

\section{Results}

The response rates were $91 \%$ for hairdressers $(n=91)$ and $84 \%$ for office workers $(n=80)$. The background variables for the hairdressers and the office workers are presented in table 1. The office workers were significantly older than the hairdressers. Significantly more hairdressers $(50 \%)$ smoked than office workers $(32 \%)$, and the hairdressers who smoked did so more than the office workers who smoked (12 $v 9$ cigarettes).

The hairdressers worked 32 hours a week on average and the office workers 36 hours. The mean employment time was 14 years for hairdressers and 16 years for office workers $(\mathrm{p}=0.15)$. The hairdressers treated (using air dye, permanent oil, bleaching powder) 13 customers a week, the oldest hairdressers (over 40 years) treated 15 customers and the youngest (under 30 years old) 11 customers each week.

The prevalences of hay fever and asthma did not differ significantly between the hairdressers and office workers as a whole (table 2), but office workers reported significantly more eczema than did hairdressers $(p=0.05)$.

In age stratified analyses, hairdressers older than 40 reported more asthma $(p=0.04)$, but less eczema $(p=0.04)$ than the office workers in the same age group.

The occurrence of atopy in the family did not differ significantly between the age stratified groups.

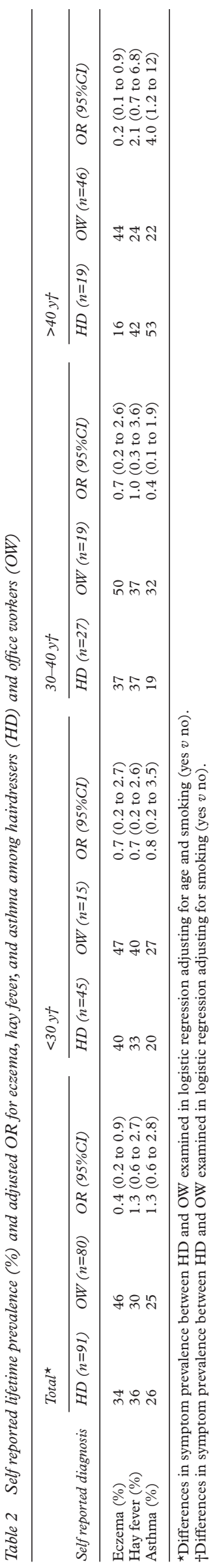


Table 3 Reported prevalences (\%) and adjusted ORs for symptoms of wheezing, breathlessness, or runny nose, among hairdressers and office workers after specific exposures

\begin{tabular}{|c|c|c|c|}
\hline Exposures & $\begin{array}{l}\text { Hairdressers with } \\
\text { symptoms (\%) }\end{array}$ & $\begin{array}{l}\text { Office workers } \\
\text { with symptoms } \\
(\%)\end{array}$ & $\begin{array}{l}\text { Adjusted OR } \\
(95 \% \mathrm{CI})\end{array}$ \\
\hline Tobacco smoke & 41 & 41 & \\
\hline Car exhaust & 17 & 19 & \\
\hline Perfume or spray* & 41 & 21 & $2.7(1.5$ to 5.6$)$ \\
\hline Food & 5 & 14 & \\
\hline Organic solvents & 41 & 29 & $1.9(1.0$ to 3.8$)$ \\
\hline Newspapers & 12 & 12 & \\
\hline Pollen & 29 & 29 & \\
\hline Animal hair & 19 & 15 & \\
\hline House dust mites & 21 & 24 & \\
\hline Medicines & 3 & 11 & \\
\hline Hair dye† & 30 & 4 & $11.4(2.7$ to 47$)$ \\
\hline Permanent oil $\dagger$ & 31 & 5 & 8.7 (2.2 to 35$)$ \\
\hline Bleaching powder $†$ & 44 & 3 & $20 \quad$ (4.3 to 96$)$ \\
\hline Bleaching dye† & 39 & 4 & $8.2(2.2$ to 31$)$ \\
\hline
\end{tabular}

*Adjusted for atopy, age, and smoking in logistic regression.

†Adjusted for atopy, age, and smoking in logistic regression, limited to hairdressers and those office workers reporting use of any hair treatment products.

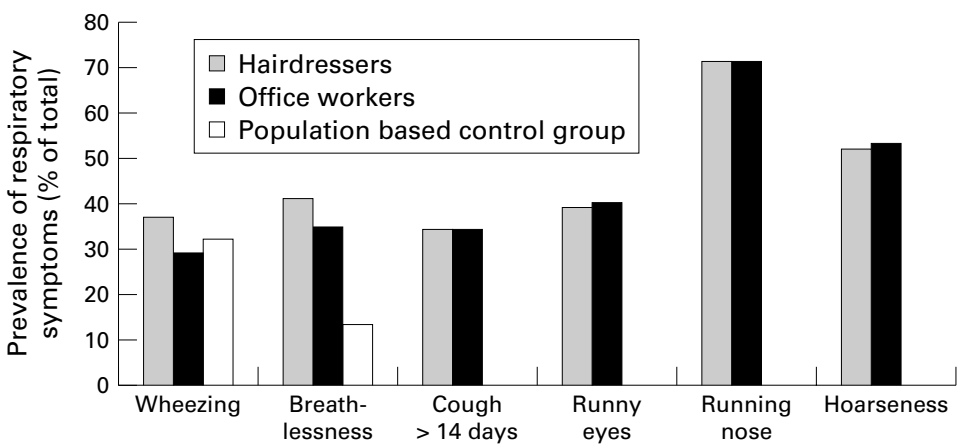

Figure 1 Prevalence of respiratory symptoms in the past year among hairdressers, office workers, and a population based control group.

Eleven per cent of the hairdressers and 15\% of the office workers had been treated by a physician or hospital for asthma.

The prevalences and odds ratio for airway symptoms during exposure to different types of pollutants are presented in table 3 . The prevalence of symptoms during exposure to the different pollutants were similar in the two groups, except that the hairdressers reported significantly more wheezing, breathlessness, runny eyes, and stuffed or runny nose when they were exposed to hair dyes, permanent oils, bleaching powder, and other chemicals used in a hairdressing salon. The hairdressers treated their own hair with chemicals (chemical treatment was defined as yes if they answered at least 1-5 times in their lifetime for the questions about how often they were dying, bleaching, or using permanent oils in their own hair) more often than the office workers (92\% $v 68 \%$ ). Office workers who did not treat their

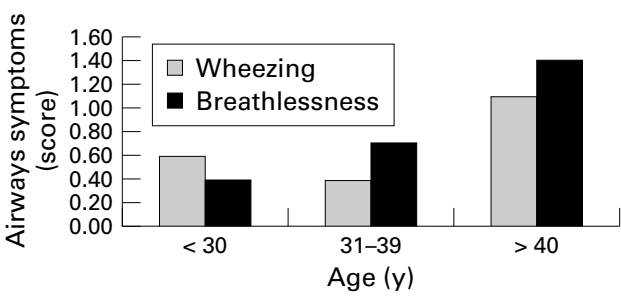

Figure 2 Wheezing and breathlessness in the past year among hairdressers. Airways symptoms score: $0=$ never symptoms; $1=y e s$ once in a while; $2=$ at least once each month.

own hair are not exposed to hairdressing chemicals. In our questionnaire they answered that they had no symptoms when they where not exposed, because of this we excluded them from the calculations.

As differences in age, atopy, and smoking may influence the results, the odds ratios of the defined respiratory conditions adjusted for these factors are presented in table 3.

The hairdressers and office workers did not differ overall in the prevalence of respiratory symptoms in the past year (yes or no, fig 1). The odds ratios for respiratory symptoms in the past year were calculated and adjusted for age, atopy, and smoking (table 4). The hairdressers over 40 reported significantly more symptoms - such as wheezing and breathlessness in the past year-than did the office workers of the same age (table 4 ). The questionnaire asked how often in the past year (daily, weekly, each month, once in a while) hairdressers and the office workers had airway symptoms. The oldest hairdressers reported symptoms-such as wheezing and breathlessness-more often than did the younger hairdressers (fig 2). These differences in breathlessness (linear regression, $\mathrm{p}=0.02$ ) and wheezing (linear regression, $p=0.04$ ) among younger and older hairdressers were significant after adjusting for smoking. The same trend was not found among the office workers.

\section{POPULATION BASED CONTROL GROUP}

The odds ratios for respiratory symptoms in the past year for hairdressers and the population based control group were calculated and adjusted for age and smoking (table 5). The differences in the prevalence of breathlessness were significant for the younger ( $<30$ years) and the older ( $>40$ years) women. The differences in the prevalence of wheezing were not significant in any age group after adjusting

Table 4 Prevalences (\%) and adjusted ORs for respiratory symptoms during the past year among hairdressers and office workers

\begin{tabular}{|c|c|c|c|c|c|c|}
\hline \multirow[b]{2}{*}{ Symptoms } & \multicolumn{3}{|l|}{ Total * } & \multicolumn{3}{|l|}{$>40 y t$} \\
\hline & Hairdresser & $\begin{array}{l}\text { Office } \\
\text { worker }\end{array}$ & OR $(95 \% C I)$ & Hairdresser & $\begin{array}{l}\text { Office } \\
\text { worker }\end{array}$ & OR $(95 \% C I)$ \\
\hline Wheezing & 37 & 29 & $1.1(0.8$ to 1.6$)$ & 56 & 24 & $3.3(1.0$ to 11$)$ \\
\hline Breathlessness & 41 & 35 & $1.2(0.8$ to 1.8$)$ & 68 & 33 & $3.9(1.1$ to 14$)$ \\
\hline Cough $>14$ days & 34 & 34 & $1.1(0.8$ to 1.6$)$ & 33 & 29 & $1.0(0.3$ to 3.4$)$ \\
\hline Runny eyes & 39 & 41 & $0.9(0.7$ to 1.4$)$ & 50 & 48 & $1.7(0.5$ to 5.6$)$ \\
\hline Runny nose & 71 & 71 & $1.0(0.6$ to 1.5$)$ & 61 & 72 & $0.3(0.1$ to 1.3$)$ \\
\hline Hoarseness & 53 & 54 & $1.0(0.7$ to 1.4$)$ & 56 & 52 & $0.9(0.3$ to 3.3$)$ \\
\hline
\end{tabular}

*Adjusted for atopy, smoking, and age (logistic regression).

†Adjusted for atopy and smoking (logistic regression). 


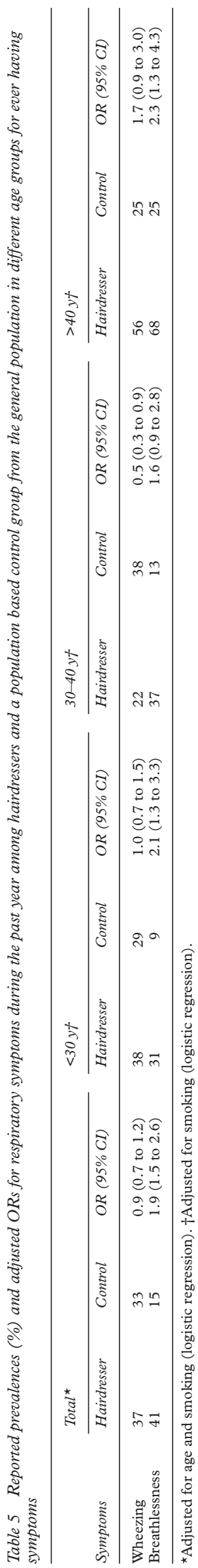

for smoking. No information on atopy was available in the population based control group.

We used symptoms in the past year for office workers and ever having symptoms in the population based control group. Office workers younger than 30 years of age reported significantly more symptoms - such as breathlessness - than did the population based control group of the same age. In women over 40 , the two groups did not differ significantly. There were no significant differences in symptoms such as wheezing between office workers and the population based control group.

\section{Discussion}

This study has shown that the prevalence of airway symptoms was similar between hairdressers and office workers in Bergen during the past year. However, hairdressers over 40 reported significantly more wheezing and breathlessness than similar aged office workers and the younger hairdressers. The oldest hairdressers also reported more asthma and hay fever than the younger hairdressers and the office workers, whereas the oldest hairdressers reported less eczema then the office workers. Office workers under 30 years of age reported more atopy (hay fever, eczema, and asthma) than did hairdressers in the same age group. These findings may be interpreted as the presence of a healthy worker effect, supported by the observation that many hairdressers have to leave this occupation prematurely because of hand eczema. ${ }^{15}$ It is impossible to work regularly as a hairdresser with hand eczema because hairdressers have to wash their hands often during the day. This probably reduces the prevalence of eczema in this group. The situation for airway symptoms is different. Hairdressers who develop airway symptoms related to specific chemicals at work might be able to avoid these chemicals most days. But still they will have some exposure every day, and this exposure can cause more respiratory symptoms - such as wheezing and breathlessness - among the oldest hairdressers. The oldest hairdressers also had more customers than the younger ones.

Hairdressers are exposed to a broad range of irritative and allergenic chemicals in their work. ${ }^{2}$ Few studies have been published on the prevalence of respiratory symptoms and diseases. ${ }^{10}$ The prevalences of upper respiratory symptoms - such as cough and runny eyes - in hairdressers in the present study are similar to those among hairdressers in Finland. ${ }^{10}$ Leino et al also concluded that the prevalences of respiratory symptoms among hairdressers are unacceptably high. Bakke et al showed that $9 \%$ of a general population in Bergen not exposed to dust or gas reported breathlessness and $16 \%$ reported wheezing. ${ }^{16}$ However, in our study group of hairdressers and office workers, the prevalences of wheezing and breathlessness were lower than the estimated prevalence of these symptoms in the general population of Bergen.

Bakke et al found eczema in $38 \%$ of women of 20-29 years, and in 36\% of women of 30-39 years. ${ }^{17}$ This is about the same as the prevalence among the hairdressers; the office workers reported more.

In both study groups the prevalence of asthma-like symptoms (wheezing and breathlessness) was much higher than in the general population in the Nordic countries. ${ }^{18}$ The reason why we did not find any differences between hairdressers and office workers was that the office workers did not represent a common population of women. The office workers reported significantly more symptoms - such as breathlessness - than did the population based control group. These findings agree with our other results, as our study shows differences between the two control groups. ${ }^{12}$ Our control group of office workers reported more asthma-like symptoms than did women from the population based control group. At the time of this study, indoor air among office workers was of current interest and was being discussed in the newspapers. Many office workers complained about poor ventilation and a lack of fresh air at work. The interest in indoor air quality may explain some of the high prevalences of reported symptoms among office workers in this study. This is confirmed by the results from the population based group who had less symptoms. The sick building syndrome was focusing on office buildings and not in the same way on industrial workplaces - such as hairdressing salons. ${ }^{11}$

This study used a self administered questionnaire. This is an inexpensive method of examining a population. A questionnaire is useful for assessing well defined work taskssuch as those in our questionnaire. ${ }^{19}$ The clinical manifestations may, however, vary greatly for self reported diagnosis of eczema, asthma, and hay fever. However, this was the case for both exposed and unexposed groups. A respiratory symptom questionnaire may also avoid some of the bias related to the diagnoses of the subjects.

The validity of self reported respiratory symptoms may differ in various groups; smokers tend to underreport respiratory symptoms because they are considered normal in smokers. ${ }^{20}$ Fifty per cent of the hairdressers and $32 \%$ of the office workers were current smokers. This means that respiratory symptoms might have been underreported among the hairdressers. ${ }^{21}$ Despite this, the oldest hairdressers reported more symptoms than did a general population. ${ }^{16}$

We used a population based control group from another study, the responders in that study answered a standardised questionnaire. ${ }^{20}$ Our questionnaire was made up of almost the same questions as that of Omneaas et al. We asked for symptoms in the past year and Omenaas asked for symtoms ever, because of this the prevalences could be highest in the population based group. That study was carried out 8 years before our survey, but there is no documentation that airways symptoms have increased in this period.

Recall bias might be a problem in questionnaire studies. Some hairdressers might recall airway symptoms better than office workers. 
However, the hairdressers also wanted to express their thoughts that hairdressing is a nice occupation, and airway symptoms might therefore have been underreported.

The known confounders (age, atopy, and smoking) of asthma and chronic bronchitis were important and were thus included in the logistic regression model when the prevalences and incidences of respiratory symptoms were calculated. Other factors may influence the data, but this is not likely.

The response rate was very high, and the hairdressers were randomly selected from different hairdressing salons. The selected salons included both members and nonmembers of the employers' federation. This means that the results from this study are representative for hairdressers in general and not only the hairdressers represented in the study.

The hairdressers are exposed to different irritating chemicals every day. The prevalences of symptoms related to the exposure of hairdressers to hairdressing chemicals are very high. We have shown in this study that hairdressers, and especially the oldest ones, have more asthma like symptoms than the control groups. One reason for this can be that the past exposures were higher, and some of the products have also been changed.

Further work is needed to prevent work place exposures in hairdressing salons. Follow up studies should be performed to assess the effects of reducing exposure to hairdressing chemicals.

This study was financially supported by the Confederation of Norwegian Business and Industry. The important contribution of the local board of the hairdresser employers' federation in parts of this work is gratefully acknowledged, as is the contribution from employers and employees in each hairdressing salon and office companies. We thank Grace Egeland for her help with the statistical analysis.

1 Bradshaw LM, Fishwick D, Slater T, et al. Chronic bronchitis, work related respiratory symptoms, and pulmonary function in welders in New Zealand. Occup Environ Med 1998;55:150-4.
2 Winder $\mathrm{C}$. Chemical hazards and health effects of hairdressing. F Occup Health Safety Aust N Z 1993;9:359-71.

3 Hollund BE, Moen BE. Chemical exposure in hairdresser salons: effect of local exhaust ventilation. Ann Occup Hyg 1998;42:277-81.

4 Muiswinkel WJ van, Kromhout $\mathrm{H}$, Onos $\mathrm{T}$, et al. Monitoring and modelling of exposure to ethanol in hairdressing salons. Ann Occup Hyg 1997;41:235-47.

5 Blainey $\mathrm{AD}$, Ollier $\mathrm{S}$, Cundell $\mathrm{D}$, et al. Occupational asthma in a hairdressing salon. Thorax $1986 ; 41: 42-50$.

6 Frosch PJ, Burrows D, Camarasa JG, et al. Allergic reactions to a hairdressers' series: results from nine European centres. Contact Dermatitis 1993;28:180-3.

7 Occupational exposures of hairdressers and barbers and personal use of hair colorants; some hair dyes, cosmetic colorants, industrial dyestuffs and aromatic amines. IARC Monogr Eval Carcinog Risks Hum 1993;57.

8 Sutthipisal N, McFadden JP, Cronon E. Sensitization in atopic and non-atopic hairdressers with hand eczema. Contact Dermatitis 1993;29:206-9.

9 van der Walle HB, Brunsveld VM. Dermatitis in hairdressers. I. The experience of the past 4 years. Contact Dermatitis $1994 ; 30: 217-21$.

10 Leino T, Tammilehto L, Luukkonen R, et al. Self reported respiratory symptoms and diseases among hairdressers. Occup Environ 1997;54:452-5.

11 Skov P, Valbjorn O, Pedersen BV, et al. Influence of indoor climate on the sick building syndrome in an office environment. The Danish Indoor Climate Study Group. Scand $\mathcal{F}$ Work Environ Health 1990;16:363-71.

12 Omenaas E, Bakke P, Elsayed S, et al. Total and specific serum IgE levels in adults: relationship to sex, age and environmental factors. Clin Exp Allergy 1994;24:530-9.

13 Gulsvik A. Prevalence of respiratory symptoms in the city of Oslo. Scand F Respir Dis 1979;60:275-85.

14 Foss OP, Lund-Larsen PG. Serum thiocyanate and smoking: interpretation of serum thiocyanate levels observed in a large health study. Scand f Clin Lab Invest 1986; 46:245-51.

15 Holm JO, Veierød MB. An epidemiological study of hand eczema. Acta Derm Venereol (Stockh) 1994;187:8-27.

16 Bakke P, Eide GE, Hanoa R, et al. Occupational dust or gas exposure and prevalences of respiratory symptoms and asthma in a general population. Eur Respir f 1991;4;273-8.

17 Bakke P, Gulsvik A, Eide GE. Hay fever, eczema and urticaria in southwest Norway. Allergy 1990;45:515-22.

18 European Community Respiratory Health Survey. Variations in the prevalence of respiratory symptoms, self reported asthma attacks, and use of asthma medication in the European Community Respiratory Health Survey (ECRHS). Eur Respir F 1996;9:687-95.

19 Wiktorin C, Vingard E, Mortimer M, et al. Interview versus questionnaire for assessing physical loads in the population-based MUSIC-Norrtälje Study. Am f Ind Med 1999;35:441-55.

20 Burney PG, Britton JR, Chinn S, et al. Descriptive epidemiology of bronchial reactivity in an adult population: results from a community study. Thorax $1987 ; 42: 38-44$.

21 Burney P, Chinn S. Developing a new questionnaire for measuring the prevalence and distribution of asthma. Chest 1987;91:79S-83S.

\section{Answers to multiple choice questions on Patch testing in occupational dermatology} by D J Gawkrodger on pages $823-828$

(1) (a) false; (b) true; (c) false; (d) false; (e) true

(2) (a) false; (b) true; (c) true; (d) true; (e) false

(3) (a) false; (b) true; (c) false; (d) false; (e) true

(4) (a) false; (b) false; (c) false; (d) true; (e) true

(5) (a) false; (b) true; (c) true; (d) false; (e) true 